\title{
ESTILOS
}

DOI: https://doi.org/10.11606/issn.1981-1624.v00i0 p342-357.

\section{Artigo \\ Autismo e inclusão no ensino regular: o olhar dos professores sobre esse processo}

\author{
Joice Otávio Ponce; Jorge Luís Ferreira Abrão
}

Resumo. A inclusão de crianças com autismo no Brasil tem se tornado uma realidade, demonstrando a efetividade das políticas de inclusão, de forma geral. No entanto, as especificidades do autismo colocam em relevo algumas idiossincrasias, sendo necessário um olhar mais apurado sobre o tema desenvolvido. Tendo em vista que a função do professor é essencial na estrutura e no funcionamento do sistema educacional, o presente artigo tem por objetivo compreender a visão destes sobre o processo inclusivo. Para que tal objetivo fosse alcançado, realizou-se entrevistas individuais semiestruturadas com quatro professoras que, no momento da pesquisa, atuavam em classes regulares nas quais estão incluídas pelo menos uma criança com autismo. A partir dos relatos, foi possível constatar a necessidade de formação especializada, já que esta foi destacada como principal elemento gerador de angústia para as professoras. Mesmo com relatos de algumas dificuldades, pode-se perceber narrativas de boas experiências com relação à inclusão.

Palavras-chave: autismo; inclusão; psicanálise.

\section{Autismo e inclusión en la educación regular: la perspectiva de los profesores a respecto de este proceso.}

Resumen. La inclusión de niños con autismo en Brasil se transforma en una realidad, lo que puede demonstrar la efectividad de las políticas de inclusión, de manera general. Aunque los avanzos, las especificidades del autismo plantean algunas idiosincrasias, así es necesario que se mire más atentamente al tema desenvuelto. Tomando en cuenta la función del profesor en la estructura y en el funcionamiento del sistema educacional, el presente artículo tiene como objetivo comprender su visión a respecto del proceso inclusivo. Para esto, realizamos entrevistas individuales semi-estructuradas con cuatro profesoras que, en el momento de las pesquisas, actuaban en clases regulares en las cuales estaban incluidos al menos un niño con autismo. Por medio de los relatos, fue posible constatar que la necesidad de formación especializada es el principal elemento generador de la angustia para las profesoras, sin embargo, a pesar de las dificultades, hay relatos de experiencias interesantes.

1. Graduanda em Psicologia e bolsista do Programa Institucional de Bolsa de Iniciação Científica, Universidade Estadual Paulista, Assis, SP, Brasil. E-mail: joice.otavio@gmail.com

2. Professor associado do Departamento de Psicologia Clínica, Universidade Estadual Paulista, Assis, SP, Brasil. E-mail: jlfabrao@gmail.com 
Palabras clave: autismo; inclusión; psicoanálisis.

\title{
Autism and inclusion in the regular education: the view of the teachers about this process
}

\begin{abstract}
The autistic kids inclusion in Brazil has become a reality, that proves the efficiency of the inclusion political. However, the specifies of autism put in view some idiosyncrasy, with makes necessary a more detailed looked about the theme. Bearing in mind that the function of the teacher is essential on the structure and functioning of the educational system, this article has as objective comprehend them view about the inclusion system. To this end we carry out an interview, individual and semi structured with four teachers, whom intervene in regular classes, in the moment of interview, which are included at least one autistic kid. As of reports was possible determine that the necessity of specialized education is the principal element generator of anguished for the teachers, however, although the difficult, we can find reports of amazing experiences related with the inclusion.
\end{abstract}

Keywords: autism; inclusion; psychoanalysis.

$\mathrm{P}$ ara dar início à reflexão sobre a inclusão de crianças com autismo no ensino regular, é necessário que se tenha uma compreensão mais aprofundada sobre o assunto, sendo assim, tecemos um breve resumo das perspectivas teóricas sobre o autismo e um percurso histórico sobre a inclusão escolar. Após a mencionada exposição, foram apresentados os resultados da pesquisa, a qual foi realizada com quatro professoras de uma escola municipal do interior do estado de São Paulo, por meio de entrevistas individuais semiestruturadas, cujo objetivo era investigar a opinião das mesmas sobre a inclusão de crianças com autismo em classes regulares. Por fim, com a finalidade de sistematizar os dados colhidos e encontrar elementos de convergência presentes na fala das professoras, tecemos as conclusões.

\section{Perspectivas teóricas sobre o autismo}

Utilizando o termo autismo cunhado por Bleuler para se referir a um dos sintomas fundamentais da esquizofrenia, Leo Kanner e Hans Asperger, foram pioneiros no estudo dessa temática, com suas publicações em 1943 e 1944, respectivamente. O trabalho do primeiro foi reconhecido logo após sua publicação, enquanto os estudos de Asperger, provavelmente por terem sido publicados em língua alemã no período pós-guerra, ganharam notoriedade apenas na década de 1980, através do trabalho da psiquiatra Lorna Wing (Wing, 1991).

Desde os estudos iniciais de Kanner (1943), muitos outros autores se dedicaram ao trabalho com crianças que apresentavam as características típicas do autismo, formulando diferentes hipóteses e posições teóricas. A partir de tais trabalhos, surgiu a inevitável discussão acerca da etiologia do autismo, que se dividiram, principalmente, em duas posições teóricas básicas: a teoria de natureza psicogênica e a teoria de natureza organogênica (Kupfer, 1999).

Para os psicanalistas - representantes da abordagem psicogênica - o autismo se destacou como um objeto de estudo privilegiado porque no mesmo período em que Kanner definiu o autismo como uma patologia que se estrutura nos primeiros anos de vida, a Psicanálise apontava um particular interesse pela relação mãe-bebê e pela clínica da primeira infância. No entanto, apesar de partirem de um mesmo referencial teórico, diferentes pressupostos sobre a etiologia do autismo foram postulados pelos autores (Cavalcanti \& Rocha, 2007). 
Para Tustin (1984), pautada pela teoria kleiniana, o autismo é uma defesa resultante de um encontro traumático do recém-nascido com o mundo externo, que compromete toda sua vida psíquica. Dito de outro modo: é como se a criança com autismo se recusasse a entrar no mundo humano.

Já para Kupfer, Laznik, Jerusalinsky e outros autores de inspiração lacaniana, o autismo surgiria a partir de uma falha no estabelecimento da operação significante, que ocorre quando o Outro materno é incapaz de introduzir o bebê na ordem simbólica, impossibilitando, dessa forma, a constituição das relações especulares e do circuito pulsional. Existem outros autores, entre eles Winnicott, que, por sua vez, colocam em discussão a necessidade de diferenciar o autismo das psicoses infantis e alertam para os potenciais efeitos negativos desse diagnóstico (Cavalcanti \& Rocha, 2007; Kupfer, 1999).

Por outro lado, os organicistas, representados principalmente por Michel Rutter e Lorna Wing, atribuem a causa do autismo a alguma disfunção bioquímica, genética ou neuropsicológica (Facion, 2005).

Para se adequar às novas descobertas sobre o autismo, advindas das diferentes posições teóricas, os manuais de psiquiatria modificaram constantemente seus critérios e agrupamentos classificatórios. Historicamente, o CID-9 (Classificação Internacional de Doenças) publicado em 1975, foi o primeiro manual a se referir ao termo autismo, o incluindo na categoria das psicoses infantis. Antes disso, a primeira e segunda edição do DSM (Manual Estatístico e Diagnóstico de Transtornos Mentais), publicadas em 1952 e 1968, respectivamente, se referiam apenas a esquizofrenia infantil (Martins, 2012).

Com a influência do trabalho de Michael Rutter em 1978, a teoria organicista passou a ser predominante, de modo que o autismo se desvinculou do diagnóstico de psicose infantil, passando a ser definido como um Transtorno Invasivo do Desenvolvimento, noção que foi incorporada pelo DSM-III em 1980. A fim de tornar os critérios de classificação equivalentes e evitar equívocos entre os pesquisadores que trabalham em diferentes partes do mundo, a décima edição do CID, também incorporou a categoria de Transtorno Invasivo do Desenvolvimento para se referir ao autismo (Klin, 2006).

Além disso, em 1979, em parceria com Judith Gould, Lorna Wing definiu a tríade sintomática do autismo. As autoras consideraram o autismo como uma síndrome que apresenta comprometimentos em três importantes áreas do desenvolvimento humano: na interação e compreensão social, na comunicação e imaginação e nos interesses e comportamentos restritos. Esse agrupamento, que ficou popularmente conhecido como Tríade de Lorna Wing, continua sendo utilizado como base para os diagnósticos clínicos atuais, tendo sido incorporado inclusive pelos manuais de psiquiatria para delimitar seus critérios nosológicos (Martins, 2012).

No DSM-IV, publicado em 1994, além do Transtorno Autista, foram adicionados ao grupo dos Transtornos Invasivos do Desenvolvimento, a Síndrome de Asperger, o Transtorno Desintegrativo, a Síndrome de Rett e os quadros atípicos ou sem outra especificação (Brasil, 2013). Todos esses transtornos são caracterizados por alterações qualitativas nas três grandes áreas de comprometimento já citadas, podendo apresentar variações clínicas quanto ao perfil da sintomatologia ou quanto ao grau de acometimento. Entre as particularidades, podemos citar que a Síndrome de Rett e o Transtorno Desintegrativo, invariavelmente, estão associados à deficiência mental, enquanto no Transtorno Autista e no autismo atípico o déficit mental pode ou não estar presente, já a Síndrome de Asperger, está associada à inteligência normal (Klin, 2006). 
Em 2013, com a publicação do DSM-V, o autismo ganhou a nova denominação de Transtorno do Espectro Autista, na qual se fundiram o autismo, o Transtorno Desintegrativo da Infância e as Síndromes de Asperger e Rett (Araújo \& Neto, 2014). Essa fusão refletiu uma visão científica, influenciada pelo pensamento de Lorna Wing, de que tais transtornos não são verdadeiramente distintos, pois os sintomas característicos de todos eles representam um contínuo único de prejuízos que podem ter intensidades variadas (Baptista \& Bosa, 2012).

Vale ressaltar que os critérios classificatórios apresentados pelos manuais de psiquiatria, apesar de auxiliarem no diagnóstico do autismo, devem ser utilizados pelos profissionais de maneira crítica. Tal afirmação decorre do fato de que os diferentes saberes que se dedicaram a produzir teorias sobre o autismo também acabaram produzindo representações sociais, que fazem com que a noção de autismo, muitas vezes, esteja associada a uma suposta ausência de subjetividade, que focaliza apenas o que essas crianças não têm, sem deixar espaço para refletir sobre seu potencial de desenvolvimento (Cavalcanti \& Rocha, 2007).

Tendo em vista a exposição feita até aqui, é possível constatar que a reflexão teórica sobre o autismo é bastante complexa. Na literatura ainda persiste a controvérsia, inaugurada desde os estudos iniciais de Kanner, se o autismo seria decorrente de um relacionamento inadequado com a mãe ou de deficiências inatas da criança; a provável razão para isso, de acordo com Camargo e Bosa (2012), é o fato de que essa dúvida perpassa a eterna discussão sobre a relação mente-corpo. Contudo, as autoras ressaltam que seja qual for o sistema de classificação ou modelo teórico adotado, existe consenso sobre a tríade sintomática.

Por fim, fica evidente que, apesar das dificuldades e controvérsias, a compreensão sobre o autismo foi significativamente ampliada ao longo das últimas décadas e que, pelo fato de ainda não haverem verdades absolutas e nem propostas terapêuticas definitivas, é necessário que os profissionais assumam uma postura flexível, capaz de acolher todas as diferentes concepções sobre o assunto (Brasil, 2013).

\section{Perspectivas históricas da inclusão escolar e suas repercussões no Brasil}

Sabendo das especificidades na forma de se relacionar e de se comunicar de uma criança com autismo, fica clara a importância da inclusão escolar e dos professores para enriquecer suas experiências sociais e pedagógicas e também para ampliar suas possibilidades no presente e futuro. Assim, para melhor entendimento, é oportuno apresentar uma breve evolução histórica da inclusão.

A partir da noção de idiotia estabelecida por Esquirol, as discussões sobre doença mental partiram de dois pontos de vista distintos: por um lado, Esquirol e seu discípulo Pinel defendiam que esse estado é definitivo e irreversível, por outro, alguns estudiosos, especialmente Jean Itard e Edward Seguin, acreditavam que se fossem utilizados métodos especiais o prognóstico poderia ser positivo (Marfinati, 2012).

Em 1798, dois anos antes da publicação da obra de Pinel "Traité médico-philosophique sur l'alienation mentale", que é considerada o marco fundador da clínica psiquiátrica e da preocupação etiológica concernente à deficiência mental, foi encontrado nas florestas do sul da França, um "menino selvagem” que recebeu o nome de Victor. Encaminhado a Paris, o menino foi atendido por Pinel que, após avaliá-lo, concluiu que não havia esperança em relação a sua educabilidade. Posteriormente, seus cuidados ficaram sob a responsabilidade de Itard, que acreditou ser possível integrá-lo à sociedade utilizando métodos educacionais 
adequados. Com esse esforço, Itard foi o primeiro a tentar educar um indivíduo com deficiência, e dessa forma, contrariando os preceitos da época, começou a ser traçada a história da Educação Especial (Banks-Leite \& Galvão, 2000).

Contudo, apesar de alguns tímidos avanços, a Educação Especial teve um lento desenvolvimento, de modo que, antes das duas guerras mundiais, a institucionalização em asilos e manicômios constituiu-se como a principal resposta social para o tratamento dos ditos desviantes. Somente com o advento da escolaridade obrigatória e devido à incapacidade das escolas em responder às demandas educacionais dos alunos considerados difíceis, começaram a surgir classes especiais dentro das escolas regulares (Mendes, 2006).

Entre as décadas de 1960 e 1970, a integração entre a educação especial e o ensino regular passou a ser mais efetiva, influenciada principalmente por três aspectos: os movimentos sociais pelos direitos humanos, que chamaram a atenção da população sobre os prejuízos da segregação de grupos minoritários; a crise mundial do petróleo que tornava inviável a continuidade de programas paralelos; e o avanço cientifico, que constatou a capacidade de aprendizagem de pessoas com deficiência (Mendes, 2006).

No que se refere aos documentos internacionais que contribuíram para inclusão escolar, a Declaração de Salamanca é de grande relevância. Produzida no ano de 1994, em conferência internacional sobre os "Princípios, Políticas e Práticas em Educação Especial", a declaração foi responsável por difundir mundialmente a filosofia da inclusão escolar, tornando possível a ascensão de teorias e práticas inclusivas em muitos países, dentre eles o Brasil.

No Brasil, o primeiro marco significativo para a educação de pessoas com deficiência, foi a Lei de Diretrizes e Bases da Educação Nacional (LDB)- Lei n ${ }^{\circ}$ 4024/61, que apontou o direito à educação para pessoas com deficiência, preferencialmente dentro do sistema regular de ensino. Contudo, apesar de sugerir a inclusão, a LDB não adaptou o sistema educacional para acolher as pessoas com deficiência, desse modo, as escolas especiais continuaram sendo a principal estratégia adotada pelos pais para a educação de seus filhos (Brasil, 2008).

Com a Constituição de 1988, que garantiu que a educação é direito de todos e que o Estado deve ofertar atendimento educacional especializado, privilegiando a rede regular de ensino, tornou-se consensual que as escolas comuns representavam o meio mais eficiente para combater as atitudes discriminatórias (Nunes, Azevedo \& Schmidt, 2013). Além disso, reforçando essa ideia, o Estatuto da Criança e do Adolescente (ECA)- Lei n ${ }^{\circ}$ 8060/90, determinou, em seu artigo $55^{\circ}$ que "os pais ou responsáveis têm a obrigação de matricular seus filhos ou pupilos na rede regular de ensino".

Em 1994, foi publicada a Política Nacional de Educação Especial, no entanto, a mesma orientava que o acesso à classe comum de escolas regulares, deveria ser destinado àqueles que possuem condições similares dos estudantes ditos "normais", para acompanhar e desenvolver os conteúdos programáticos do ensino comum (Brasil, 2008). A dicotomia entre inclusão e integração, foi corrigida somente em 1996, com a publicação de uma nova LDB, à qual, garante que é dever da escola fazer modificações para atender às necessidades de seus estudantes, abandonando, ao menos em tese, a ideia de que os estudantes deveriam se adequar aos parâmetros preconizados pela escola.

Em relação à inclusão de crianças com autismo, dois marcos importantes são, respectivamente, a Portaria 1.635/2002, que garantiu às pessoas com deficiência mental e autismo assistência por intermédio de equipe multiprofissional e multidisciplinar e a Lei 12.764/2012, que instituiu a Política Nacional de Proteção dos Direitos da Pessoa com Transtorno do Espectro Autista. 
Outra importante estratégia adotada pelo Estado para incentivar a inclusão, foi a Política Nacional de Educação Especial na Perspectiva da Educação Inclusiva, criada em 2008, que contribuiu efetivamente para a transição de alunos matriculados em escolas e classes especiais, para escolas regulares e classes comuns, tendo o aumento de 695,2\% em relação aos anos de 2000 e 2013 (Brasil, 2014).

Consideramos que o aumento expressivo no número de matrículas, de fato, representa um grande avanço para a Educação Inclusiva. No entanto, cabe ressaltar que a matrícula em classes regulares é apenas o começo do processo inclusivo e deve ser acompanhada de muitas outras práticas que favoreçam o acolhimento dessas crianças.

\section{Delineamento metodológico}

Buscando compreender a visão dos professores acerca da inclusão de crianças com autismo no Ensino Regular, foram realizadas entrevistas com quatro professoras de uma Escola Municipal de Ensino Infantil e Fundamental (EMEIF), do município de Assis-SP. Todas as professoras foram indicadas pela Secretaria Municipal da Educação (SME) e no momento da entrevista, todas elas lecionavam em classes nas quais estavam incluídas, no mínimo, uma criança com autismo.

Cada professora participou individualmente de uma única entrevista semiestruturada. Esse tipo de entrevista foi privilegiado pelo fato de possibilitar ao entrevistado discorrer com liberdade sobre o tema proposto no roteiro de entrevista, podendo começar por onde quiser e incluindo o que desejar. O entrevistador intervém somente quando houver necessidade de fazer algum apontamento que facilite a entrevista (Ocampo \& Arzeno 1995).

As entrevistas foram gravadas, transcritas e, posteriormente, analisadas com base nos conhecimentos da teoria psicanalítica, de forma a identificar categorias temáticas que representem os aspectos principais da fala dos professores em relação ao processo de inclusão.

Para melhor conhecimento do percurso profissional das participantes, a tabela abaixo traz algumas informações adicionais:

Tabela. 1. Atuação profissional das professoras

\begin{tabular}{|l|l|l|l|l|}
\hline & Professora 1 & Professora 2 & Professora 3 & Professora 4 \\
\hline $\begin{array}{l}\text { Tempo de } \\
\text { atuação }\end{array}$ & 14 anos & 25 anos & 20 anos & 28 anos \\
\hline $\begin{array}{l}\mathrm{N}^{\circ} \text { de alunos } \\
\text { incluídos }\end{array}$ & 3 & 3 & 2 & 6 \\
\hline $\begin{array}{l}\mathrm{N}^{\circ} \text { de alunos } \\
\text { com autismo } \\
\text { incluídos }\end{array}$ & 1 & 2 & 2 & 2 \\
\hline $\begin{array}{l}\text { Modalidade } \\
\text { de ensino }\end{array}$ & $\begin{array}{l}\text { Educação } \\
\text { infantil }\end{array}$ & $\begin{array}{l}\text { Educação } \\
\text { infantil }\end{array}$ & $\begin{array}{l}\text { Ensino } \\
\text { fundamental }\end{array}$ & $\begin{array}{l}\text { Ensino } \\
\text { fundamental }\end{array}$ \\
\hline
\end{tabular}

\section{Resultados e discussão}


Os resultados obtidos nas entrevistas foram divididos em cinco categorias, que abrangem os principais pontos destacados espontaneamente pelas professoras ou direcionados pelo roteiro de entrevista.

\section{A busca por formação especializada: necessidades e idealizações}

Com o movimento de 'psicologização' da educação, desencadeado no século XX, a criança passou a ser vista como um objeto que pode se ajustar ao modelo ideal de indivíduo, caso o professor aplique corretamente seus métodos. Nesse sentido, quando o professor se depara com uma criança com autismo no contexto da inclusão escolar, sente-se fracassado, pois percebe que todo o seu arsenal teórico pode não ser suficiente para fazê-la atingir os objetivos curriculares esperados (Salgado, 2012).

As falas das professoras entrevistadas se articulam com esse pressuposto, à medida que, apesar da inclusão ser vista por todas como positiva no ponto de vista social, a questão pedagógica aparece como um elemento de frustração, como exemplifica a seguinte fala da Professora 1: “(...) no comportamento a gente até dá um jeito, a gente se vira, mas no pedagógico eu me sinto perdida".

A dificuldade em relação à transmissão dos conteúdos reflete em um sentimento de despreparo. Três (Professoras 1, 2 e 3) das quatro professoras entrevistadas se referiram a necessidade de suporte para saber como lidar com as crianças, já que consideravam que a formação que tiveram não é suficiente. Até mesmo a Professora 3, que possui especialização em Educação Inclusiva, diz não estar totalmente preparada, aponta que cada criança tem sua especificidade; por isso, é preciso estar sempre buscando ajuda, de preferência em conjunto com os demais trabalhos desenvolvidos pela SME.

Partindo da definição proposta por Lajonquière (2010) de que educar consiste em transmitir marcas simbólicas que permitam a criança usufruir de um lugar do qual o desejo seja possível, compreendemos que a atuação das professoras, estando permeada de ilusões pedagógicas, não atende a esse objetivo. Pautado pelo discurso do mestre, daquele que tudo sabe, ou ainda na lógica da crise na escola moderna, daquele que se encontra no declínio de seu saber, o professor relega o aluno a uma posição de passividade em relação a sua própria aprendizagem.

Uma educação que leva em conta o sujeito, por sua vez, exige do professor uma reflexão crítica sobre sua função na estrutura educacional e, além disso, a superação de seu narcisismo, porque sob essa nova perspectiva, os resultados, amplamente valorizados pela pedagogia contemporânea, poderão, muitas vezes, estar aquém do esperado. Alberti (2008) acrescenta que há duas leis possíveis de serem transmitidas pela escola: a lei vinculada a função paterna que barra o desejo do Outro e a lei que não sustenta o sujeito enquanto desejante, tornando-o um escravo que deve satisfazer os desejos e demandas do mestre. Nesse sentido, é somente a partir da lei instaurada pela função paterna que se torna possível a formação de uma parceria verdadeira entre aluno e professor, porque ao impedi-los de fazer $U m$, torna-se possível o enlaçamento entre um e outro.

Além da reflexão individual, a constituição de uma rede de apoio formada por diretores, coordenadores, professores e demais profissionais aptos a trabalhar com autismo, favoreceria positivamente todos os envolvidos no processo inclusivo. Trabalhando em rede, a troca de conhecimentos e experiências é facilitada, de forma que os professores se sentiriam mais 
seguros para o trabalho em sala de aula, o que, por sua vez, refletiria no relacionamento com os alunos e no desenvolvimento dos mesmos. Bastos e Kupfer (2010) também salientam que a inclusão do professor em espaços de interlocução com outros profissionais é importantíssima para a inclusão, porque são eles que darão sustentação a esse lugar social, isto é, o lugar de aluno.

De acordo com as entrevistas, no município de Assis, não existe uma rede de suporte contínua, mas a experiência foi positiva em ocasiões que as professoras, por conta própria, solicitaram ajuda. As professoras 2 e 3 que relataram ter solicitado suporte à SME, o consideraram efetivo no esclarecimento das dúvidas, enquanto a Professora 1, que não solicitou suporte particular, apesar de evidenciar que precisa de ajuda, disse que a SME também oferece palestras, mas que as mesmas não são tão eficazes por serem muito abrangentes, não abarcando, desse modo, as dificuldades específicas do cuidado com seu aluno.

Não é difícil encontrar na literatura resultados similares referentes a formação do professor. No trabalho de Sant'Ana (2005), os professores se diziam cientes de seu despreparo para promover a inclusão e também apontavam para a necessidade apoio de especialistas. Do mesmo modo, o sentimento de vazio em relação a formação aparece na pesquisa de Anjos, Andrade e Pereira (2009), assim como a necessidade de se sentir instigado e incentivado diante das dificuldades e desafios encontrados.

De maneira semelhante, os professores entrevistados por De Vitta, De Vitta e Monteiro (2010) consideravam que para uma boa atuação, além dos conhecimentos necessários para facilitar a aprendizagem da criança incluída, é preciso gostar da área de educação inclusiva e se sentir motivado.

A necessidade de identificação com a área educação inclusiva também aparece durante a entrevista da Professora 2:

\begin{abstract}
Quando se fala em Educação Especial, alguma coisa assim, de repente eu acho que você tem que ter um preparo para estar assistindo essas crianças, não é? E normalmente quem faz a opção disso é quem gosta dessa área, então é uma preparação diferenciada, você tem que buscar, você tem que ir atrás, você tem que se entregar de verdade. [...] E se eu não fiz essa área é porque eu não dou conta, entendeu? Recebo, não vou achar ruim, só que eu preciso de suporte. Tento fazer o que posso, mas preciso de ajuda.
\end{abstract}

Essa fala nos faz refletir sobre a necessidade de maiores discussões sobre a Educação Inclusiva ao longo da graduação, uma vez que todos os professores podem receber alunos com deficiência em suas salas de aula, independente da identificação ou não com a área de Educação Inclusiva.

Contudo, vale ressaltar que os conhecimentos adquiridos só terão valor real se estiverem vinculados à prática cotidiana com o aluno, pois, de modo geral, todas as professoras relataram ter recebido alguma informação sobre o autismo e orientações sobre como lidar com essas crianças, mas entendem que esse conjunto de informações é insuficiente para compreender seu aluno em particular e para desenvolver uma estratégia pedagógica eficiente. Neste sentido, a busca por formação específica que auxilie o trabalho dos professores, deve ser pensada como algo capaz de promover mudanças e rupturas em modelos pedagógicos já cristalizados, e não um ideal que magicamente poderia minimizar a dificuldades encontradas.

\title{
A importância da família
}


$\mathrm{Na}$ fala das Professoras 2, 3 e 4, a família foi citada como um elemento muito importante no processo inclusivo e no desenvolvimento da criança.

\begin{abstract}
A mãe corre atrás de tudo; atendimento com psicólogo, atendimento com fonoaudióloga, tratamento com neurologista. Então se nota bastante diferença dele comparado às outras crianças. [...] Essa mãe é uma que eu tenho muito orgulho, e ela morre de medo que ele não aprenda (Professora 4).
\end{abstract}

De acordo com as professoras dessa pesquisa e com Panerai et al. (2009), citado por Lemos et al. (2016), quando a família tem uma boa aceitação do diagnóstico e toma para si a responsabilidade pela educação dos filhos, a criança tem maiores chances de progredir, por outro lado, os problemas familiares ou o desinteresse por parte dos pais podem ser agravantes. Além disso, a Professora 2 também destaca a importância da parceria entre a família e a escola para trocar experiências e conhecer a criança em todos os contextos.

\title{
Construindo novos olhares sobre o autismo
}

O desamparo pedagógico, destacado pelas professoras como fator mais desestimulante no exercício de sua atividade, vem de encontro ao conhecimento superficial que estas possuem acerca do autismo, já permeado por contradições e ideias do senso comum. Assim como na pesquisa de Leonardo (2008), na qual a maioria dos participantes demonstraram ter pouco conhecimento sobre as necessidades de seus alunos e sobre a inclusão, as professoras desta pesquisa entendem que não possuem informações o suficiente para trabalharem com uma criança com autismo sem se sentirem inseguras.

$\mathrm{Na}$ fala das professoras aparecem elementos estigmatizados sobre o autismo que, em alguns casos, nem mesmo se articulam com a realidade do aluno incluído em sua sala de aula. Ao ser questionada sobre seus conhecimentos acerca do Autismo, a Professora 2 se referiu ao autista como uma pessoa que vive "no mundo dela", cuja aproximação com o grupo é praticamente impossível, porém, em outros trechos da entrevista, a mesma professora descreve interações de seu aluno com os demais e coloca o professor como o responsável por mediar essas interações.

Pelo que a gente está acompanhando desde o início do ano, ele foi se aproximando do grupo, então eu tento sempre o inserir em tudo, na roda de conversa, nas brincadeiras, estamos sempre chamando para o grupo. Ele gosta de carinho, ele gosta de abraçar, ele gosta do toque, coisa que muitas vezes o autista não se permite (Professora 2).

Essa contradição tem origem nos preconceitos que se disseminaram sobre o autismo ao longo da história. Segundo Cavalcanti e Rocha (2007), a matriz Kanneriana e a própria sintomatologia do Autismo induzem ao pensamento de que os autistas são seres vazios. No caso dessa professora, apesar dos estigmas lhe causarem um receio inicial e se perpetuarem mesmo após a constatação de uma realidade diferente, a experiência da inclusão parece ter tido um resultado positivo.

Até eu ter um contato maior com o Autismo isso me assustava muito, só que ele é uma criança que me surpreendeu muito e me surpreende a cada dia, porque desde 
o início ele está inserido no nosso contexto, é uma criança muito boa para se lidar (Professora 2).

Outra ideia do senso comum detectada na fala da Professora 1 se refere aos autistas terem uma "habilidade", ou seja, ao pensamento, frequentemente demonstrado em filmes, de que autistas possuem um dom especial ou uma grande capacidade intelectual. No entanto, na rotina com seu aluno essa expectativa não se efetiva, o que lhe causa um grande desespero em relação à questão pedagógica. A visão idealizada sobre a aprendizagem da criança com autismo parece interferir na confiança dos professores enquanto profissionais e, além disso, também pode atrapalhar o próprio processo de ensino e aprendizagem, pois ao esperar um grande desempenho da criança, os pequenos progressos podem passar despercebidos, sendo desvalorizados.

A falta de conhecimento sobre a dificuldade de simbolização, característica do autismo, é outro elemento que interfere na relação entre professor e aluno no contexto da inclusão. Devido à falta de elementos simbólicos adequados para responder a determinadas situações, como a fala, por exemplo, alguns autistas podem acabar expressando suas emoções pela via da atuação, como cita a professora 1: "ele não interage, ele só é agressivo mesmo. Quando ele quer uma coisa ele vai e toma, se não consegue por bem, ele vai no tapa, mas interação não há, nenhuma".

No trecho destacado, a professora descreve uma interação de seu aluno, mesmo que não a reconheça como tal. Ao interpretar suas atitudes apenas como "agressividade", e não como uma "resposta" que está de acordo com suas possibilidades simbólicas, o professor fica impedido de atribuir novos significados as vivências de seu aluno.

Ele não briga e não é agressivo, mas em alguns momentos ele se irrita. Teve uma fase que ele tinha medo de pássaro, então ele chorava e ficava quietinho. No pátio tem farelo, então vem um monte de passarinho e ele tinha medo, as vezes ele dizia 'é um gorila', sabia que era pássaro, porém ele ficava com medo. Então eu explicava 'não, é só um passarinho, se você fizer assim ele vai embora. Vamos lá, eu vou te levar até ele, você vai ver que ele vai voar e vai embora', então aí vai amenizando (Professora 2).

O trecho citado não se refere a um episódio de agressividade, mas é um exemplo correto de como o professor pode auxiliar o autista a entender suas emoções e a lidar com elas, seja o medo, a raiva ou até mesmo a alegria. Para isso, ele deve estar atento ao fato de que por trás de um gesto aparentemente agressivo ou estereotipia pode existir um ato comunicativo ou expressivo.

É essencial que todo educador tenha conhecimento da condição autista e de suas peculiaridades, contudo, vale destacar que a formação teórica não representa todo o universo da prática pedagógica inclusiva. Como destaca Cacciari, Lima e Bernardi (2005) e De Vitta, De Vitta e Monteiro (2010), a postura pessoal do professor deve ser sensível, de modo a favorecer aceitação do aluno e de sua identidade.

\section{Vantagens da inclusão: a aprendizagem para além do pedagógico}

As vantagens da inclusão citadas pelas professoras também foram mencionadas por Camargo e Bosa (2009). Dentre elas podemos destacar a possibilidade de oportunizar ao autista a convivência com outras crianças que poderão lhe oferecer um modelo de interação. 
Nas palavras da Professora 3: a oportunidade de "aprender com crianças normais", enquanto os demais aprenderão a lidar com as diferenças, pois terão que "conviver com isso lá fora".

Para que a inclusão também seja vantajosa para os demais alunos, a Professora 2 destaca a importância de o professor atuar como um mediador entre a criança autista e o restante da sala.

Vai depender do esclarecimento que você vai ter com a turma, porque assim, é muito a postura de quem vai estar conduzindo a sala. Porque se as crianças perceberem que a professora tem aversão pela criança que está sendo incluída, óbvio que os alunos também terão essa visão, mas se você traz a criança para o grupo, aí eles vão vendo de uma maneira normal (Professora, 2).

A importância da inclusão para os familiares também foi elencada como uma vantagem, de acordo com a Professora 2 atualmente a família quer que a criança esteja incluída em todos os contextos, diferente do que ocorria antigamente.

Assim, evidencia-se que a inclusão, além de abordar questões pedagógicas especificas, circunscritas ao campo do ensino-aprendizagem, proporciona uma experiência de aprendizagem muito mais ampla, que se efetiva pelo contato com outros alunos e pela experiência advinda da convivência em ambientes que proporcionam novas demandas a criança com autismo.

\section{Desvantagens da inclusão: a dificuldade de incluir as diferenças em um contexto escolar massificado}

A falta de um acompanhante capacitado para orientar a criança também foi citada pelas professoras como um dos grandes desafios para inclusão. De acordo com a Lei $n^{\circ}$. 12.764/2012, que institui a Política Nacional de Proteção dos Direitos da Pessoa com Transtorno do Espectro Autista (Brasil, 2012), a criança autista inclusa no ensino regular tem direito a um acompanhante especializado quando comprovada a necessidade.

No município de Assis esse acompanhamento é feito por estagiários bolsistas dos cursos de Fisioterapia, Nutrição, Pedagogia e Psicologia, no entanto, de acordo com a opinião das Professoras 1, 2 e 3 o suporte oferecido por eles muitas vezes é deficitário: "Eu acho que por direito, pelo que vi a lei, ele teria direito a um professor especial para ajudá-lo, porque nem eu, e nem o bolsista que cuida dele, temos essa experiência, não temos isso, essa bagagem para ajudá-lo (Professora 1)", "Muitas vezes vem estagiário que não é nem da área, muitas vezes eu observo que não está acrescentando nada a criança (Professora 2)", "Os estagiários que ficam com eles, muitos não são da área de psicologia e pedagogia, entendeu? Então é muito difícil para eles saberem como lidar com a criança (Professora 3)".

Gomes e Mendes (2010) alertam que, embora a presença de um acompanhante seja um recurso valioso, o baixo nível de instrução dos mesmos pode comprometer o exercício de sua função. Nesse sentido, as autoras defendem que a oferta de acompanhantes leigos, não pode substituir o apoio de profissionais especializados e qualificados para responder às necessidades diferenciadas destas crianças.

Além disso, o conflito enunciado pelas professoras, referente à divisão entre ensino regular e ensino especializado, foi discutido por Glat (2018). Para a autora, as políticas públicas e as construções teórico-conceituais evoluem em ritmo mais acelerado que as representações 
sociais, por conta disso, após décadas de políticas de inclusão, ainda não foi possível desconstruir a visão dos professores acerca dessa dicotomia. Para superar esse estigma, que perpassa também as considerações sobre criança "normal" e criança "anormal", a proposta é de um trabalho colaborativo entre o professor regente do ensino comum e o professor especializado, o que tornaria possível desenvolver alternativas criativas e diversificadas para todos os alunos.

Contudo, apesar dessa problemática, a Professora 4, talvez por sua maior experiência com a inclusão, se referiu de maneira positiva ao trabalho do estagiário, a mesma acredita que se ele for capaz de ouvir as orientações dadas por ela e acreditar no que está sendo trabalhado, conseguirá ajudar a criança a se desenvolver.

O excesso de alunos, citado pelas Professoras 3 e 4 e o tamanho físico da sala de aula, citado apenas pela professora 3 , também foram destacados como aspectos desvantajosos para a inclusão. O problema do excesso de alunos, segundo ela, é que o barulho da sala acaba causando irritação ao autista, ou ao contrário, o barulho que ele faz acaba tirando o foco das outras crianças. De acordo com outra professora, é justamente o grande número de alunos que faz a presença de um acompanhante necessária, pois acredita que sozinha não conseguiria dar conta de todos.

Apesar das desvantagens citadas, a aceitação dos alunos não parece estar sendo feita de maneira forçada para cumprir as necessidades legais de matrícula como no trabalho de Briant e Oliver (2012), no qual as professoras não viam possibilidades reais de aprendizagem para os alunos incluídos.

\section{Considerações finais}

Relacionando os dados obtidos nas entrevistas da pesquisa e as informações da pesquisa bibliográfica, foi possível constatar que a inclusão de crianças com autismo no Brasil tem se tornado uma realidade, demonstrando a efetividade das políticas de inclusão de forma geral. No entanto, as especificidades do autismo colocam em relevo algumas idiossincrasias, sendo necessário que um olhar mais apurado sobre o tema desenvolvido. Neste contexto, a presente pesquisa abordou as principais vicissitudes da inclusão de crianças autistas no ensino regular, por intermédio do olhar dos professores que atuam diretamente neste contexto.

Em linhas gerais, há um pleno reconhecimento de que a inclusão é um caminho favorável que possibilita a diminuição do preconceito e de práticas de exclusão social; apesar disso, fica evidente que o reconhecimento da importância da inclusão, por si só não é capaz de romper com antigos paradigmas que tendem a promover resistências frente a esta nova realidade. Neste sentido, muito do que foi mencionado pelas professoras decorre da dificuldade em abandonar paradigmas tradicionais de normalidade e anormalidade que ainda permeiam as relações escolares e que são conservadas em seu imaginário, como a antiga divisão entre educação especial e ensino regular.

No cenário brasileiro, a maior dificuldade para inclusão de crianças com autismo, segundo os professores, é falta de formação especializada. Ainda que o acolhimento desses alunos em sala de aula seja menos angustiante para o professor quando a criança não possui problemas de aprendizagem e/ou comportamentos agressivos, de acordo com as professoras, o maior problema da inclusão não diz respeito à impossibilidade de manter o aluno com autismo na escola regular e sim a necessidade de os professores estarem preparados para recebê-los. 
A formação deficitária dos professores dificulta a possibilidade de abordar a inclusão do aluno com autismo a partir de um novo paradigma educacional, contudo, ainda que a formação superior realmente possa ser melhorada, por si só ela não será capaz de transformar todos os aspectos das relações estabelecidas entre os professores e seus alunos com autismo. Portanto, considerar a necessidade de melhor formação dos professores como apanágio de todas as dificuldades enfrentadas na inclusão, caminha no sentido da idealização e da manutenção do narcisismo do professor em detrimento do desejo do aluno.

No entanto, por mais que haja dificuldades, há relatos de boas experiências em relação à inclusão. A maior parte das falas se referem a aspectos positivos da criança, e, mesmo havendo ideias estigmatizadas sobre o autismo, as professoras parecem ter com seus alunos uma aproximação que permite um olhar para além do transtorno autista.

Para tornar a experiência inclusiva mais eficiente para as crianças e menos angustiante para os professores, seria necessário formar uma rede de apoio mais forte entre as professoras e a SME. Como foi constatado, as orientações ocasionais solicitadas pelas professoras tiveram um bom resultado para as mesmas. Sendo assim, seria válido que esse tipo de suporte fosse frequente. Levando em conta o que foi dito pelas professoras, também seria interessante incluir os estagiários nessa rede, para que os mesmos possam se capacitar para o trabalho com as crianças e fortalecer os vínculos com as professoras.

Além da transmissão de conteúdo teórico, a importância da formação de uma rede de apoio também está na oportunidade de criar um espaço de fala e escuta para o professor que, por si só, é terapêutico. Como destacaram Cacciari, Lima e Bernardi (2005), oportunizar ao professor um espaço para falar de suas vivências e angústias permite que ele ressignifique sua prática e descubra possibilidades reais de atuação.

É fundamental que o fazer educativo esteja pautado na singularidade do aluno, de modo que o professor respeite suas dificuldades sem, no entanto, ficar preso a elas, pois, no contexto da inclusão, o professor deve ter um olhar que veja potenciais a serem desenvolvidos. Sua postura deve visar a emancipação do sujeito e de seu desejo, o que só é possível a partir de uma rejeição às idealizações pedagógicas e de uma disponibilidade para encontrar algo diferente do que pregam as metáforas criadas para se referir ao autismo, porque partindo desse lugar de antemão será negado ao aluno a possibilidade de construção de vínculos, expressão de sentimentos e apreensão da realidade.

Nesse sentido, compreendemos que a inclusão deve ir muito além da aprendizagem dos conteúdos curriculares, o professor deve ser aquele que, antes de qualquer coisa, humaniza a criança que está diante dele, somente dessa forma, aluno e professor podem construir juntos uma nova visão sobre o autismo no mundo contemporâneo.

\section{Referências}

Anjos, H. P.; Andrade, E. P. \& Pereira, M. R. (2009). A inclusão escolar do ponto de vista dos professores: o processo de constituição de um discurso. Revista Brasileira de Educação, 14(40), 116-129. DOI: $10.1590 /$ S1413-24782009000100010

Alberti, S. (2008). O adolescente e o outro. Rio de Janeiro: Jorge Zahar.

Araújo, A. C. \& Neto, F. L. (2014). A nova classificação americana para os transtornos mentais- o DSM-5. Jornal de Psicanálise, 46(85) 99-116. DOI: 10.31505/rbtcc.v16i1.659 
Banks-Leite, L. \& Galvão, I. (2000) Uma introdução a história de Victor do Aveyron e suas repercussões. In: Banks-Leite, L. \& Galvão, I. (Org.), A Educação de um selvagem - As experiências pedagógicas de Jean Itard. (Vol. 1, pp. 11-24) São Paulo: Cortez.

Baptista, C. R.\& Bosa, C. A. (2012). Autismo e Educação: Reflexões e Propostas de Intervenção. Porto Alegre: Artmed.

Bastos, M. B. \& Kupfer, M. C. M. (2010). A escuta de professores no trabalho Inclusão Escolar de crianças psicóticas e autistas. Estilos da Clínica, 15(1), 116-125. DOI: 10.11606/issn.19811624.v15i1p116-125

Brasil. (1996). LEI No 9.394 de 20 de dezembro de 1996. Lei de Diretrizes e Bases da Educação $\begin{array}{llllll}\text { Nacional. } & \text { Texto em } & \text { 2017: }\end{array}$ https://www2.senado.leg.br/bdsf/bitstream/handle/id/70320/65.pdf

Brasil. Ministério da Educação. (2008). Política Nacional de Educação Especial na Perspectiva da Educação Inclusiva. Texto recuperado em 02 abr. 2017: http://portal.mec.gov.br/index.php?option=com_docman\&view=download\&alias=16690-politicanacional-de-educacao-especial-na-perspectiva-da-educacao-inclusiva-05122014\&Itemid=30192

Brasil. (2012). LEI No 12.764 de dezembro de 2012. Política Nacional de Proteção dos Direitos da Pessoa com Transtorno do Espectro Autista. Texto recuperado em 12 dez. 2017: http://www.planalto.gov.br/ccivil_03/_ato2011-2014/2012/lei/112764.htm

Brasil. Ministério da Saúde. (2013). Linha de cuidado para a atenção integral as pessoas com transtorno do espectro do autismo e suas famílias no Sistema Único de Saúde. Brasília: Ministério da Saúde. Texto recuperado em 22 fev. 2017: http://bvsms.saude.gov.br/bvs/publicacoes/linha_cuidado_atencao_pessoas_transtorno.pdf

Brasil. Ministério da Educação. (2014). Relatório Educação Para Todos no Brasil 2000-2015. Texto recuperado em 25 fev. 2017: http://portal.mec.gov.br/index.php?option=com_docman\&view=download\&alias=15774-eptrelatorio-06062014\&Itemid $=30192$

Briant, M. E. P. \& Oliver, F. C. (2012). Inclusão de crianças com deficiência na escola regular numa região do município de São Paulo: conhecendo estratégias e ações. Revista Brasileira Edição Especial, 18(1), 141-154. DOI: 10.1590/S1413-65382012000100010

Cacciari, F. R., Lima, F. T. \& Bernardi, M. R. (2005). Ressignificando a prática: Um caminho para a inclusão. Construção Psicopedagógica, 13(10), 0-0. Recuperado em 21 abr. 2017: http://pepsic.bvsalud.org/scielo.php?script=sci_arttext\&pid=S1415-69542005000100011

Camargo, S. P. H \& Bosa, C. A. (2012). Competência Social, Inclusão Escolar e Autismo: Um Estudo de Caso Comparativo. Psicologia: Teoria e Pesquisa, 28(3), 315-324. DOI: 10.1590/S010237722012000300007

Cavalcanti, A. E. \& Rocha, P. S. (2007). Autismo: Construções e Desconstruções. $3^{\mathrm{a}}$ edição. São Paulo: Casa do Psicólogo.

De Vitta, F. C. F., De Vitta, A. \& Monteiro, A. S. R. (2010). Percepção de professores de educação infantil sobre a inclusão da criança com deficiência. Revista Brasileira de Educação Especial, 16(3), 415-428. DOI: 10.1590/S1413-65382010000300007

Facion, J. R. (2005). Transtorno Autista e Psicose na Criança- Histórico. In: Facion, J. R. Transtornos Invasivos do Desenvolvimento e Transtornos de Comportamento Disruptivo. (pp. 19-64). Curitiba: Editora Index.

Glat, R. Desconstruindo Representações Socais: por uma Cultura de Colboração para Inclusão Escolar. Rev. Bras. Ed. Esp., 24, Edicação Especial, 9-20. DOI: 10.1590/s141365382418000400002 
Gomes, C. G. S. \& Mendes, E. G. (2010). Escolarização inclusiva de alunos com autismo na Rede Municipal de Ensino de Belo Horizonte. Revista Brasileira de Educação Especial, 16(3), 375-396. DOI: $10.1590 / \mathrm{S} 1413-65382010000300005$

Kanner, L. (1943). Autistic disturbances of affective contact. Nervous child. Recuperado em 15 dez. 2018: http://mail.neurodiversity.com/library_kanner_1943.pdf

Klin, M. (2006). Autismo e Síndrome de Asperger: uma visão geral. Revista Brasileira de Psiquiatria, 28(1), p. 03-11. DOI: 10.1590/S1516-44462006000500002

Kupfer M. C. (1999). Psicose e autismo na infância: problemas diagnósticos. Estilos da Clínica, 4(7), 96-107. DOI: 10.11606/issn.1981-1624.v4i7p96-107

Lajonquière, L. (2010). Figuras do infantil: a psicanálise na vida cotidiana com as crianças. Petrópolis, RJ: Vozes.

Lemos, E. L. M. D. et al. (2016). Concepções de pais e professores sobre a inclusão de crianças autistas. Fractal: Revista de Psicologia, 28(3), 251-261. DOI: 10.1590/1984-0292/1229

Leonardo, N. S. T. (2008). Inclusão escolar: um estudo acerca da implantação da proposta em escolas públicas. Revista Semestral. da Associação. Brasileira de Psicologia Escolar e Educacional (ABRAPEE), 12(2), 431-440. DOI: 10.1590/S1413-85572008000200014

Marfinati, A. G. (2012). Um estudo histórico sobre as práticas psicanalíticas institucionais com crianças autistas no Brasil. Tese de Mestrado, Faculdade de Ciências e Letras da Universidade Estadual Paulista Júlio de Mesquita Filho, Assis. Texto recuperado em 25 abr. 2017: https://repositorio.unesp.br/bitstream/handle/11449/97628/marfinati_ac_me_assis.pdf?sequence=1

Martins, C. P. (2012). Face a face com o Autismo: será a Inclusão um mito ou uma realidade? Dissertação de Mestrado, Escola Superior de Educação João de Deus, Lisboa. Texto recuperado em dez. 2018: https://comum.rcaap.pt/bitstream/10400.26/2562/1/ClaudiaMartins.pdf

Mendes, E. C. (2006). A radicalização do debate sobre inclusão escolar no Brasil. Revista Brasileira de Educação, 11(33), 387-359. DOI: 10.1590/S1413-24782006000300002

Nunes, P., Azevedo, D. R. \& Schmidt, M. Q. O. (2013). Inclusão educacional de pessoas com Autismo no Brasil: uma revisão da literatura. Revista Educação Especial, 26(47), 557-572. DOI: $10.5902 / 1984686 \times 10178$

Ocampo, M. L. S. \& Arzeno M. E. G. A. (1995). Entrevista Inicial. In: Ocampo, M. L. S.; Arzeno M. E. G.; Piccolo, E. G. et al. O Processo Psicodiagnóstico e as Técnicas Projetivas. São Paulo: Martim Fontes. p. 14-46.

Salgado, A. M. (2012). Impasses e passos na inclusão escolar de crianças autistas e psicóticas: o trabalho do professor e olhar para o sujeito. Tese de Mestrado, Universidade Federal do Paraná, $\begin{array}{lllll}\text { Curitiba. } & \text { Recuperado } & \text { em } & 22 & \text { ago. }\end{array}$ https://acervodigital.ufpr.br/bitstream/handle/1884/28518/R\%20-\%20D\%20$\% 20$ ANDRESSA \%20MATTOS\%20SALGADO.pdf?sequence $=1 \&$ isAllowed=y

Sant'Ana, I. M. (2005). Educação inclusiva: concepções de professores e diretores. Psicologia em Estudo, 10(2), 227-234. DOI: 10.1590/S1413-73722005000200009

Tustin, F. (1984). Estados autísticos em crianças. Rio de Janeiro: Imago.

Wing, L. (1991) The relationship between Asperger's syndrome and Kanners's autism. In U. Frith (Ed.) Autism and Asperger syndrome. Cambriage University Press, 93-121.

Recebido em março/2019 - Aceito em agosto/2019. 